\title{
Survival of Secondary Sporidia of Floret-Infecting Tilletia Species: Implications for Epidemiology
}

\author{
Blair J. Goates
}

U.S. Department of Agriculture-Agricultural Research Service, 1691 S. 2700 W., Aberdeen, ID 83210.

Accepted for publication 12 February 2010.

\begin{abstract}
Goates, B. J. 2010. Survival of secondary sporidia of floret-infecting Tilletia species: Implications for epidemiology. Phytopathology 100:655662.

Secondary sporidia of Tilletia horrida, T. indica, and T. walkeri initiate local infection of rice, wheat, and ryegrass florets, respectively, leading to disease in seed. Secondary sporidia are considered to be fragile and short lived. To examine this, secondary sporidia from agar cultures of these species were naturally discharged onto petri dish lids and were air-dried and maintained in the laboratory at 10 to $20 \%$ relative humidity (RH) at 20 to $22^{\circ} \mathrm{C}$, and at 40 to $50 \% \mathrm{RH}$ at $18^{\circ} \mathrm{C}$. Lids were periodically inverted over fresh agar to determine viability of dried sporidia. Sporidia held

generated rapidly. Commonly, $18 \mathrm{~h}$ after lids with dried sporidia were inverted over agar, newly produced secondary sporidia had discharged onto the agar and produced extensive hyphal growth. There was no difference in the viability of sporidia that were initially dried rapidly or dried slowly over $10 \mathrm{~h}$. Sporidia of $T$. horrida or $T$. indica dried on petri dish lids placed in the lower canopy of barley or wheat fields in Idaho and Arizona during early flag leaf to soft dough stages and held until crops were near or beyond maturity regenerated rapidly despite temperatures up to $46^{\circ} \mathrm{C}$ and several days of $\mathrm{RH}<20 \%$. These results suggest that sporidia produced well prior to susceptible growth stages of the host can lay dormant in very dry field environments and then rapidly regenerate under humid rainy conditions associated with the diseases.
\end{abstract} 31 to 49 days at 10 to $20 \% \mathrm{RH}$ and 56 to 88 days at 40 to $50 \%$ RH re-
The smut fungi Tilletia horrida, T. indica, and T. walkeri cause the seed diseases kernel smut of rice, Karnal bunt of wheat, and ryegrass bunt, respectively. The diseases have similar characteristics with regard to being caused by local infection of florets via air-borne secondary sporidia that originate from germinated teliospores near the soil surface. Infection typically results in partially diseased grains at maturity. Rice smut is considered a minor disease that occurs throughout the rice growing regions of the world, but it occasionally causes significant losses in yield and quality $(4,11)$. Karnal bunt is also considered to be a minor disease that occurs in a few regions of the world and only rarely causes significant yield and quality losses $(7,32,35)$. However, Karnal bunt is a disease of considerable concern due to quarantine regulations of numerous countries $(6,32)$. T. walkeri has only recently been described as a species infecting ryegrass (9). This disease apparently has been in the United States for some time but went unnoticed due to low levels of infection and the cryptic nature of disease symptoms. Teliospores of T. walkeri were detected during sensitive seed wash assays for $T$. indica teliospores in the United States and the species was initially misidentified as T. indica based on morphological and molecular analyses (6). Ryegrass bunt has not been a significant seed production problem. A review of the history and biology of these species has been presented recently (8). Little has been published on the biology or

Corresponding author: B. J. Goates; E-mail address: Blair.Goates@ ars.usda.gov

The use of trade, firm, or corporation names in this publication is for the information and convenience of the reader. Such use does not constitute an official endorsement or approval by the United States Department of Agriculture of the Agricultural Research Service of any product or service to the exclusion of others that may be suitable.

doi:10.1094/PHYTO-100-7-0655

This article is in the public domain and not copyrightable. It may be freely reprinted with customary crediting of the source. The American Phytopathological Society, 2010 etiology of $T$. walkeri, but due to its somewhat unique and very close relatedness to T. indica (10), it appears likely that it is similar to the Karnal bunt pathogen in other biological respects.

$T$. horrida and $T$. indica have thick-walled teliospores that persist for years in field soil $(5,36)$. The longevity of $T$. walkeri teliospores has not been determined. Teliospores germinating at or near the soil surface, or on water as can occur with T. horrida, develop filiform primary sporidia (basidiospores) which produce hyphae or allantoid secondary sporidia (secondary basidiospores). The allantoid secondary sporidia form and are forcibly discharged in the same manner as in other species of Tilletia (17). The secondary sporidia produce additional secondary sporidia or germinate via hyphae that produce secondary sporidia which serve as primary inoculum. A few days of cloudy or rainy weather appears to be required to enable the increase of secondary sporidia to sufficient quantities to incite disease $(11,12)$. Initial infection by $T$. indica occurs after airborne secondary sporidia are deposited on glumes and produce hyphae which penetrate stomata and eventually enter the caryopsis where the fungus proliferates and sporulates to produce a sorus filled with teliospores (15). Infection of wheat by $T$. indica can occur during spike emergence up to and including soft dough stages with high inoculum density under ideal disease-conducive conditions (18). The initial infection and period of susceptibility is not well defined in the other species (11), but appears to be very similar to that found in Karnal bunt. When grain is mature, the three diseases produce similar symptoms with regards to the partial conversion of seed into a darkcolored mass of teliospores which reduces both yield and quality.

The allantoid secondary sporidia of Tilletia spp. are thin-walled structures (17) that are assumed to be fragile and short-lived and to require very high relative humidity $(\mathrm{RH})$ to survive $(1,23$, $28,29,33,39$ ). Smilanick et al. (39) studied viability of $T$. indica sporidia in artificial atmospheres of varying $\mathrm{RH}$ created with glycerin and water and found that sporidia could not survive longer than approximately $5 \mathrm{~h}$ at $25 \% \mathrm{RH}$ and $14 \mathrm{~h}$ at $95 \%$. Except for this single study, there is little actual evidence to 
support the idea of the fragility of sporidia. Because secondary sporidia are considered to be fragile, it is thought that teliospores must germinate and produce secondary sporidia approximately the same time the crop is at susceptible heading stages $(2,11,13$, $14,22,34,37)$. However, this is inconsistent with observations that $T$. indica teliospores germinate at about the same rate on soil under field conditions in India from the middle of December to the end of February (25) which is the period that coincides with shortly after planting through wheat heading. Additionally, $T$. horrida and $T$. indica teliospores germinate in a wide range of environmental conditions in vitro $(13,38,43)$.

During an unrelated study designed to quantify secondary sporidia that were discharged from cultures, it was discovered that secondary sporidia deposited onto glass microscope slides could survive several days on a lab bench under very low humidity, contrary to previous reports $(1,23,28,29,33,39)$. The current study was conducted to examine the longevity of secondary sporidia in laboratory and field environments to determine if this could help to explain some of the inconsistencies in the current concepts of the epidemiology of these diseases.

\section{MATERIALS AND METHODS}

Laboratory experiments. Teliospores of T. horrida, $T$. indica, and $T$. walkeri originated from diseased seed of commercial crops in Arkansas, Arizona, and Oregon, respectively. The teliospores were surface-sterilized for $1 \mathrm{~min}$ with an aqueous solution of $0.25 \% \mathrm{NaOCl}$ made with commercial liquid bleach followed by two brief rinses and resuspension in sterile water. Teliospores were plated on $2 \%$ water agar (WA) (Difco, Bectin-Dickenson, Sparks, MD) in 9-cm plastic petri dishes and then incubated at 20 to $22^{\circ} \mathrm{C}$ for 7 to 15 days to induce germination and subsequent hyphal and sporidial growth. Hyphae and secondary sporidia from germination plates were subcultured periodically on $2 \%$ potato dextrose agar (PDA) (Difco, Bectin-Dickenson). During growth on WA germination plates and on PDA, naturally discharged secondary sporidia were deposited onto fresh petri dish lids placed over cultures for 1 to 2 days. Lids were then removed from the cultures and were air-dried and maintained on empty petri dish bottoms either on a laboratory bench under ambient conditions of 10 to $20 \% \mathrm{RH}$ and 20 to $22^{\circ} \mathrm{C}$, or in an incubator at 40 to $50 \% \mathrm{RH}$ and $18^{\circ} \mathrm{C}$ supplemented with $12 \mathrm{~h}$ of diurnal light from two, 40-watt fluorescent bulbs. The experiments were repeated twice for each species grown on both WA and PDA at the lower $\mathrm{RH}$, and for each species grown on PDA and/or WA at the higher RH. Temperature and humidity were monitored and/or recorded simultaneously by two of three means: (i) colorimetric humidity indicator commonly used in desiccators, (ii) digital LCD temperature and humidity monitor (Taylor, USA), and (iii) WatchDog model 150 data logger (Spectrum Technologies, Inc., Plainfield, IL). All monitors were in general agreement. Approximately every 4 to 7 days, petri dish lids with dried sporidia were placed over fresh PDA plates, sealed with Parafilm, and then incubated at 20 to $22^{\circ} \mathrm{C}$ to determine if secondary sporidia could regenerate, indicated by deposition of newly produced sporidia from the lid onto the fresh agar.

The effect of initial drying time was tested with the three species by drying lids containing sporidia: (i) by immediate exposure to $10 \% \mathrm{RH}$, (ii) over a water mist placed in a petri dish bottom, (iii) over filter paper soaked with $0.5 \mathrm{ml}$ of water placed in a petri dish, and (iv) over filter paper soaked with $1.0 \mathrm{ml}$ of water placed in a petri dish. Lids dried over the water treatments were canted slightly over the dish bottom to allow air exchange and eventual drying. After drying, the lids were placed on empty petri dish bottoms and incubated at 10 to $20 \% \mathrm{RH}$ and 20 to $22^{\circ} \mathrm{C}$ for 4 days and were then inverted over fresh PDA plates, sealed with Parafilm, and assessed for viability as described above. This experiment was repeated twice.
Field experiments. Petri dish lids with secondary sporidia of $T$. horrida or T. indica, produced and dried for 1 to 2 days at 10 to $20 \% \mathrm{RH}$ and 20 to $22^{\circ} \mathrm{C}$ in the laboratory as described previously, were taped onto wooden stakes $(30 \times 2.5 \mathrm{~cm})$ to completely expose the sporidia. The stakes were placed within the canopy of grain fields so that the lids were 20 to $25 \mathrm{~cm}$ from the soil surface with the inoculated side of the dish facing slightly toward the soil at an angle of about 70 to $80^{\circ}$. Uninoculated control lids were taped to stakes in the same manner for use in tests with $T$. indica. Additionally, controls with dried sporidia for the field experiments were held in the lab at variable temperature and $\mathrm{RH}$ as indicated in the results section.

Experiments with $T$. horrida sporidia were conducted at the University of Idaho Research and Extension Center, Aberdeen, ID. In 2005, dried sporidia were placed in a spring barley field on 23 June when the crop was at boot stage. Samples were collected up to 22 August, about 2 weeks after the barley was harvested. An area of approximately $100 \mathrm{~m}^{2}$ was left unharvested surrounding the test area to maintain the crop canopy. The experiment was repeated at Aberdeen in 2006 in a spring wheat field, beginning on 14 July when the crop was at soft dough stage. Samples were taken up to 30 August, about 2 weeks after wheat was mature. Sporidia in the 2005 experiment originated from PDA cultures and from both WA and PDA cultures in 2006. Fields in Aberdeen were given sprinkler irrigation at a rate of $4 \mathrm{~cm}$ at approximately 10-day intervals until plants were just beyond the hard dough growth stage as is performed during typical commercial grain production.

Experiments with $T$. indica sporidia from PDA cultures were conducted from 17 March to 22 May 2006 in two fields in Arizona that had a previous history of Karnal bunt. One field was near Buckeye, AZ and was planted with a commercial durum wheat crop. The wheat was at early heading growth stage when experiments began. The other field was an experimental wheat plot near Maricopa, AZ at flag leaf emerging stage at the beginning of the experiment. The fields were flood-irrigated at approximately 2 -week intervals. The experimental wheat plot near Maricopa was arranged in a 4-m strip running the length of the field bordered with forage oat in the remainder of the field. The forage oat was harvested 10 April, which removed the effect of a continuous crop canopy in the field.

Two petri dish lids were collected approximately every 7 days from the ID fields and approximately every 14 days from the two AZ fields. The lids were inverted over fresh PDA and examined for regeneration of sporidia as described above.

Temperature and RH within the crop canopy were monitored with WatchDog model 150 data loggers placed within small instrument shelters obtained from the data logger manufacturer. The data loggers were placed at the same level as lids in the field and recorded data hourly over the course of the experiments. The data loggers did not record RH below $20.7 \%$, so humidity lower than this, which occurred after crops matured and fields were dry, was estimated by calculating $\mathrm{RH}$ using the temperature of the recorder and the dew point temperature recorded by a National Atmospheric and Oceanic Administration (NOAA) instrument array placed approximately 100 to $500 \mathrm{~m}$ from the fields in ID and approximately 2 to 3 miles from the fields in AZ.

\section{RESULTS}

Laboratory experiments. Petri dish lids containing dried secondary sporidia that were generated from WA and PDA for testing had numerous sporidia deposited on the lids within 1 to 2 days after placing a new lid over the culture (Fig. 1). Secondary sporidia were able to regenerate from petri dish lids after drying for 31 to 34 days at 10 to $20 \% \mathrm{RH}$, and after 56 to 88 days at the 40 to $50 \%$ RH (Table 1). Most remarkably, sporidia dried on lids regenerated newly formed sporidia within $18 \mathrm{~h}$ after inverting 
dried sporidia over fresh agar. The regenerated sporidia had germinated and produced long hyphae within this time frame (Fig. 2). This rapid regeneration of sporidia occurred in samples taken during the early portions of the dry incubation period, as well as in samples taken toward the end of the dry incubation period. Toward the end of the dry incubation period, the colonies produced on the fresh PDA commonly covered only about 10 to $20 \%$ of the total surface of the agar, whereas samples taken earlier in the period, about $90 \%$ coverage was common. A burgundy pigment was produced in T. horrida cultures and no pigment was produced in T. indica or T. walkeri cultures.

In most experiments, the ultimate longevity of sporidia was not determined because samples were depleted before viability was

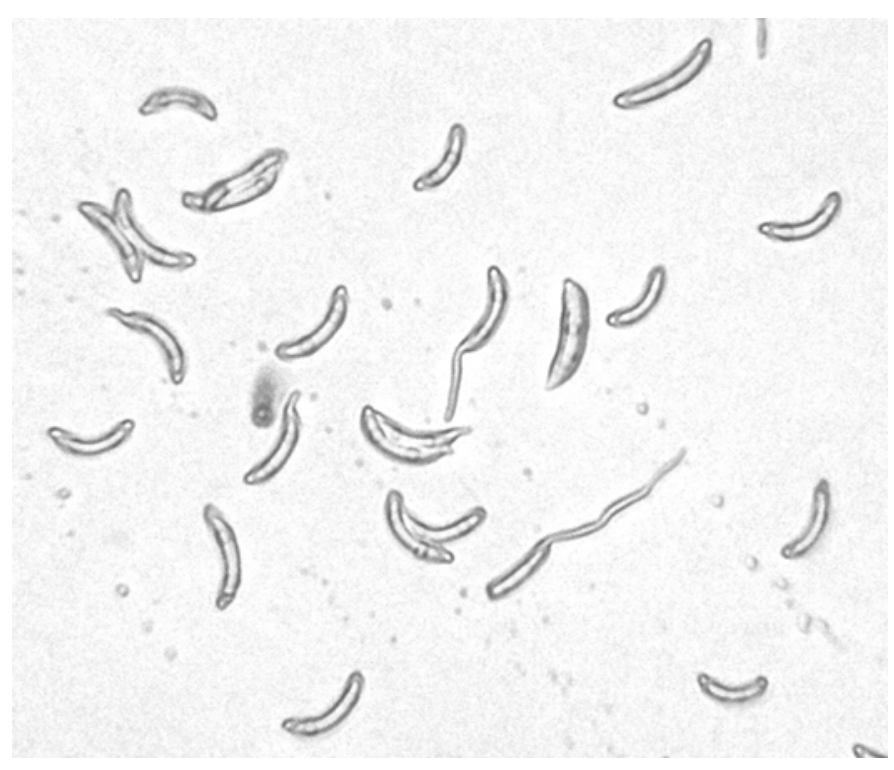

Fig. 1. Secondary sporidia of Tilletia horrida on the surface of a plastic petri dish lid dried in the laboratory at 10 to $20 \%$ relative humidity and 20 to $22^{\circ} \mathrm{C}$ for 30 days.

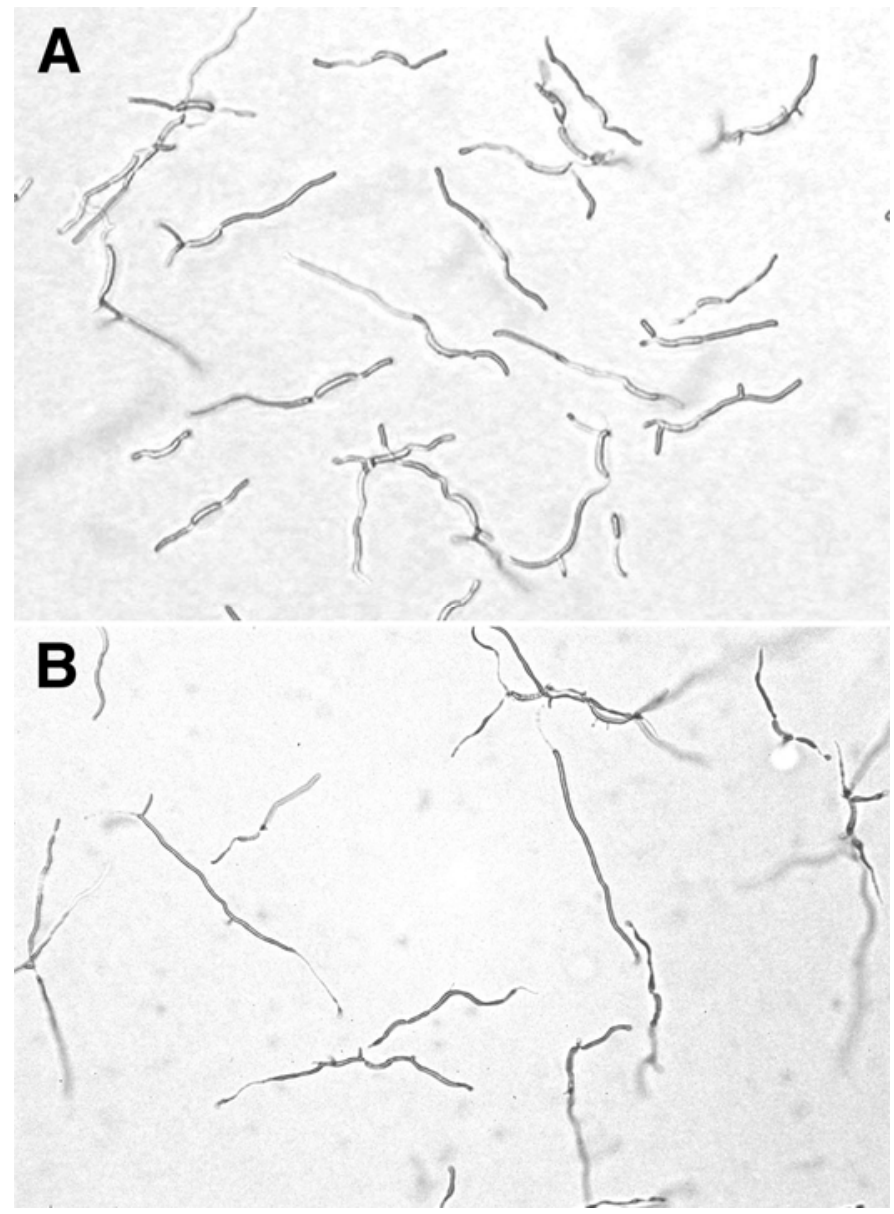

Fig. 2. Newly formed secondary sporidia of Tilletia horrida on the surface of agar. The newly formed sporidia were discharged from regenerated dried sporidia on a petri dish lid containing sporidia that were dried for 25 days at 10 to $20 \%$ relative humidity and then inverted over the agar. The sporidia were deposited on the agar and produced hyphae $18 \mathrm{~h}$ after inverting a petri dish lid containing dried sporidia.

TABLE 1. Survival period of dried secondary sporidia of Tilletia horrida, T. indica, and T. walkeri incubated in the laboratory in separate experiments at different temperature and relative humidity regimes

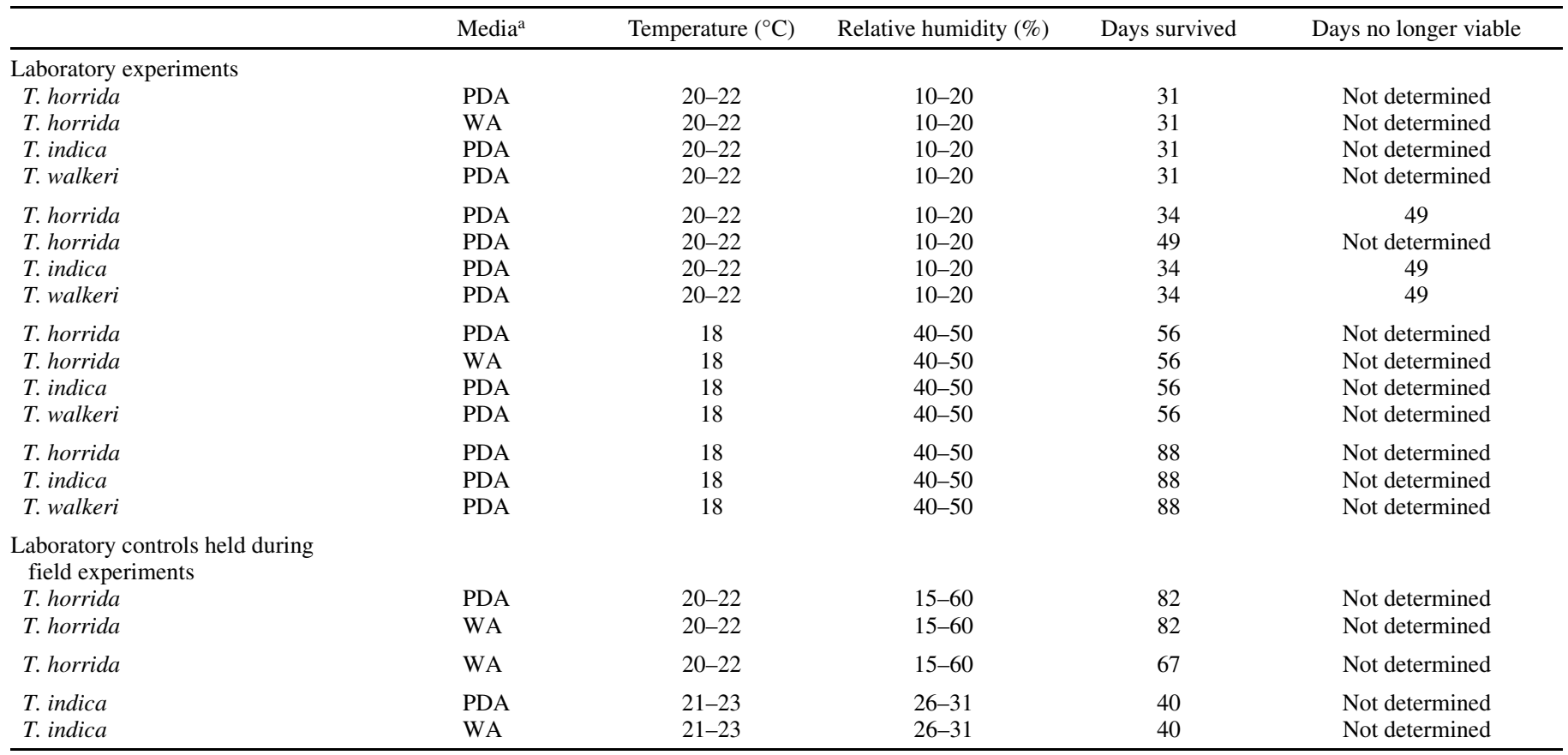

a Medium used to produce secondary sporidia prior to drying. Potato dextrose agar (PDA), water agar (WA). 
lost (Table 1). For example, the three species in one experiment were able to regenerate after 31 days at 10 to $20 \% \mathrm{RH}$, and the percent coverage of new colonies on the PDA surface ranged from 50 to $75 \%$, but further assays were not possible because all the samples prepared for that particular experiment were used in the previous assays. Similarly, samples maintained at 50 to $60 \% \mathrm{RH}$ were depleted after 56 days and 88 days in the first and second experiments, respectively, but sporidia maintained viability up to that time. Among all the experiments, the maximum survival determined at 10 to $20 \% \mathrm{RH}$ was 34 days for $T$. indica and $T$. walkeri, and 49 days for T. horrida, and 88 days at 50 to $60 \% \mathrm{RH}$ for all three species (Table 1). One set of samples of $T$. horrida sporidia originating from both WA and PDA, which were incubated in the laboratory at 20 to $22^{\circ} \mathrm{C}$ and 15 to $60 \% \mathrm{RH}$ to serve as controls during the field experiments, maintained viability after 82 days when the samples were depleted (Table 1). The longevity of viability of sporidia produced from WA and PDA was the same in all five experiments where sporidia from the two media were compared directly in both the laboratory and the field (Tables 1 and 2).

In the experiments to determine the effect of initial drying time on survival, moisture that was sometimes visibly present on the lids dried within approximately one minute after direct exposure to ambient air at $10 \% \mathrm{RH}$ in the laboratory. When initial drying time was extended by placing different amounts of water in the petri dish bottom, the moisture in the bottom dish evaporated after approximately $1 \mathrm{~h}$ in the misted plates, $4 \mathrm{~h}$ in the plates with $0.5 \mathrm{ml}$ of water, and $10 \mathrm{~h}$ in the plates with $1 \mathrm{ml}$ of water. In both experiments there was no apparent difference in the initial drying treatments, followed by 4 days at 10 to $20 \% \mathrm{RH}$, on the regeneration of sporidia after they were placed over fresh agar (Fig. $3)$. Sporidia in these experiments regenerated the same as de-

TABLE 2. Summary of high temperature and low relative humidity (RH) extremes during the period of survival of secondary sporidia of Tilletia horrida and $T$. indica placed in the canopy of grain fields in each of four separate experiments

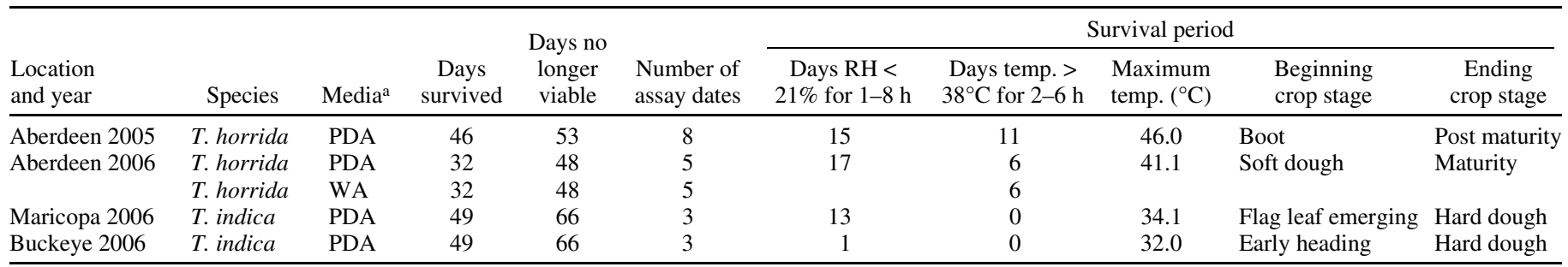

${ }^{a}$ Medium used to produce secondary sporidia prior to drying. Potato dextrose agar (PDA), water agar (WA).

\section{amendment drying time}

\section{T. walkeri}

T. horrida

\section{T. indica}

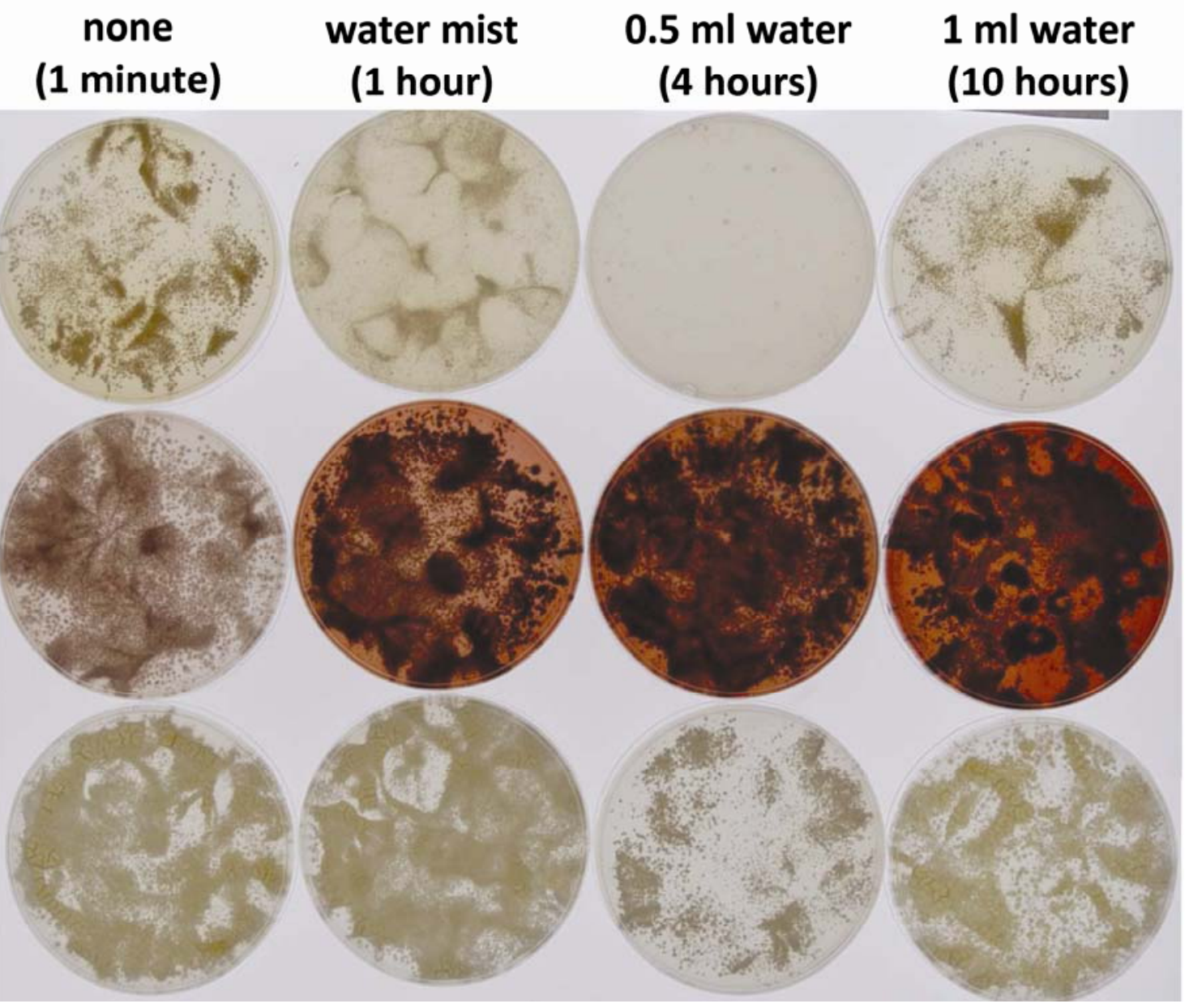

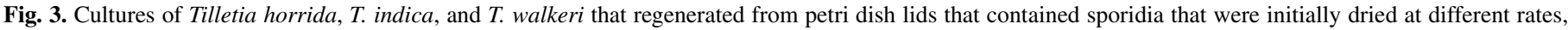

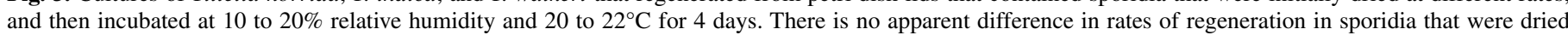
quickly or slowly over $10 \mathrm{~h}$. 
scribed previously within 18 to $20 \mathrm{~h}$ after inverting lids over fresh PDA.

Field experiments. Wide diurnal fluctuations in temperature and $\mathrm{RH}$ occurred in the field environments over the course of the experiments, in particular after the crops matured. While the crops were still green, very high humidity typically occurred every evening followed by substantial reduction in humidity and increase in temperature during the day (Fig. 4). After the crops were close to maturity and fields were dry, temperatures at the level of the sporidia samples were up to $10^{\circ} \mathrm{C}$ higher than those recorded at nearby NOAA weather stations during the day. The weather stations also often recorded $\mathrm{RH}$ as low as 10 to $15 \%$ when data recorders in the fields were reading $20.7 \% \mathrm{RH}$ which was their lower limit. Using the dew point temperature of the NOAA stations and temperature recorded in the field, it was calculated that $\mathrm{RH}$ often dropped to $10 \%$ or lower in the field when monitors indicated $20.7 \% \mathrm{RH}$ reading continuously for a few hours. Most often, dried sporidia on petri dish lids that were in the field for several days to a few weeks had essentially the same appearance as when they were originally dried (Fig. 5).

Sporidia held in the field under the influence of several diurnal periods of low humidity of about 10 to $20 \%$ and temperatures as high as $46^{\circ} \mathrm{C}$ (Table 2) regenerated within $18 \mathrm{~h}$ at the same rate as controls held in the laboratory at $\mathrm{RH}$ ranging from 15 to $60 \%$ and temperatures ranging from 20 to $23^{\circ} \mathrm{C}$. No sporidial generation occurred in uninoculated plates used as controls in the $T$. indica field tests.
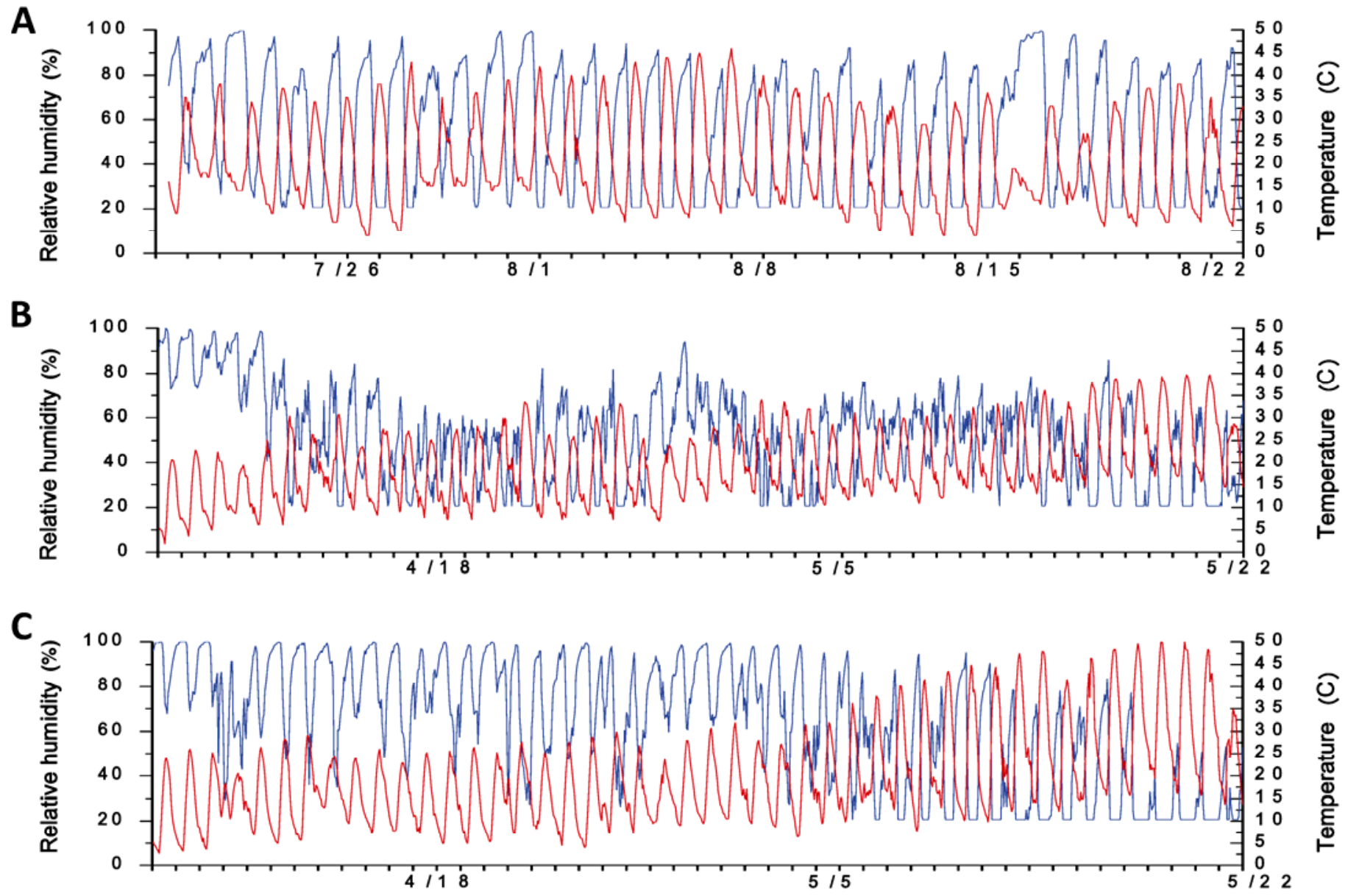

D

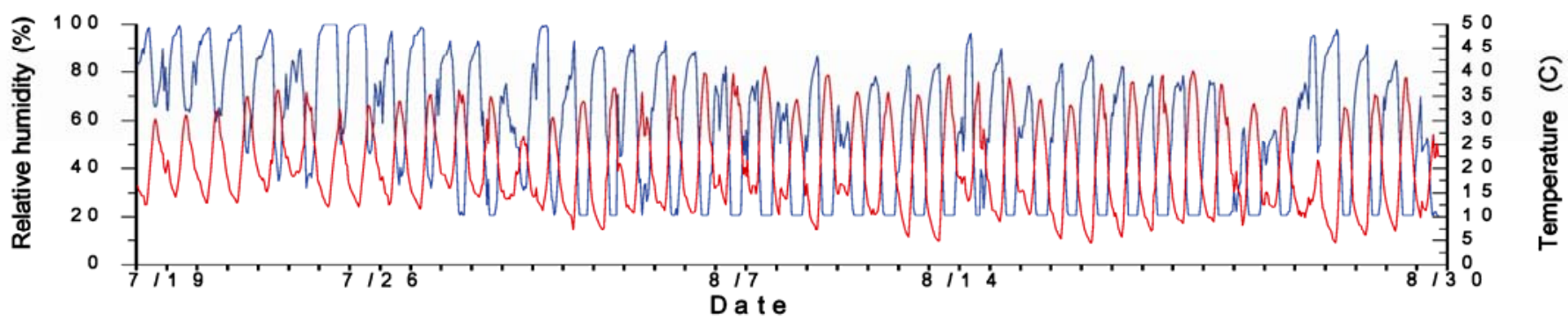

Fig. 4. Temperature (red line) and relative humidity (blue line) recorded during incubation of sporidia dried on petri dish lids placed within the canopy of grain fields. Dates indicated are the days samples were taken for a viability assay during the period. A, The later portion of the incubation period of Tilletia horrida in a spring barley field in Aberdeen. Temperature and relative humidity between 23 June and 20 July (not shown) ranged from 3 to $33^{\circ} \mathrm{C}$ and 36 to $100 \%$, respectively. The relative humidity was at or close to $100 \%$ each night during that period. Samples were viable up to 8 August. The crop was mature on 1 August. B, Incubation period of T. indica in an experimental bread wheat field in Maricopa. Samples were viable up to 5 May when crop was at hard dough stage. C. Incubation period of $T$. indica in a commercial durum wheat field. Samples were viable up to 5 May when the crop was at hard dough stage. D, Incubation period of $T$. horrida in a spring wheat field in Aberdeen. Samples were viable up to 14 August when the crop was mature. 
In the spring barley field in 2005, samples of T. horrida placed on 21 June and then removed at approximately weekly intervals had viable sporidia up to 8 August when the crop surrounding the test plot was harvested. The barley was mature on 1 August. Samples taken 15 and 24 August were not viable. Sporidia were viable after 15 days with periods of $\mathrm{RH}<21 \%$ and 14 days where the daily high temperature exceeded $35^{\circ} \mathrm{C}$, with a maximum of $46^{\circ} \mathrm{C}$ on 1 day (Fig. 4; Table 2).

In the spring wheat field in 2006, samples of T. horrida placed on 13 July and then removed at approximately weekly intervals had viable sporidia up to 14 August when the crop was mature. Samples of sporidia taken on 30 August were not viable. The sporidia maintained viability after the extremes of 17 days with periods of $\mathrm{RH}<21 \%$ and 10 days where the temperature exceeded $35^{\circ} \mathrm{C}$ with a maximum of $41^{\circ} \mathrm{C}$ on 1 day (Fig. 4; Table 2).

In the experimental wheat plots in AZ, samples of $T$. indica placed on 17 March had viable sporidia up to 4 May when the crop was at hard dough stage. Samples of sporidia taken about 2 weeks after this, when the crop was mature, were not viable. The sporidia maintained viability after 13 days with periods of $\mathrm{RH}<21 \%$, and a maximum temperature of $32^{\circ} \mathrm{C}$ on 1 day. The harvest of the forage oat surrounding the wheat plots 10 April caused a substantial drop in the $\mathrm{RH}$ in the plots (Fig. 4). The commercial durum wheat field in $\mathrm{AZ}$ had just 1 day with $\mathrm{RH}<21 \%$ and a maximum temperature of $32^{\circ} \mathrm{C}$ on 1 day during the survival period. However, the high temperatures and lower humidity that followed during a 2-week period were apparently responsible for rendering the sporidia nonviable (Fig. 4; Table 2).

Contamination from various fungi and bacteria was often a problem in lids taken from fields after they were placed over fresh agar. However, the smut hyphae could be identified by the production of diagnostic secondary sporidia. In some cases, the cultures that resulted from dishes taken from the field were inverted over fresh PDA for 4 to $8 \mathrm{~h}$ during which secondary sporidia were discharged onto the fresh plate and produced nearly pure cultures of the smut fungi with characteristic morphology.

\section{DISCUSSION}

There are numerous reports of the fragile nature of secondary sporidia of $T$. indica $(1,23,28,29,33,39)$ but only one (39) contains results of experimentation. Smilanick et al. (39), who used artificial atmospheres of varying RH created with glycerin and water, reported that sporidia survived no longer than $14 \mathrm{~h}$, even at

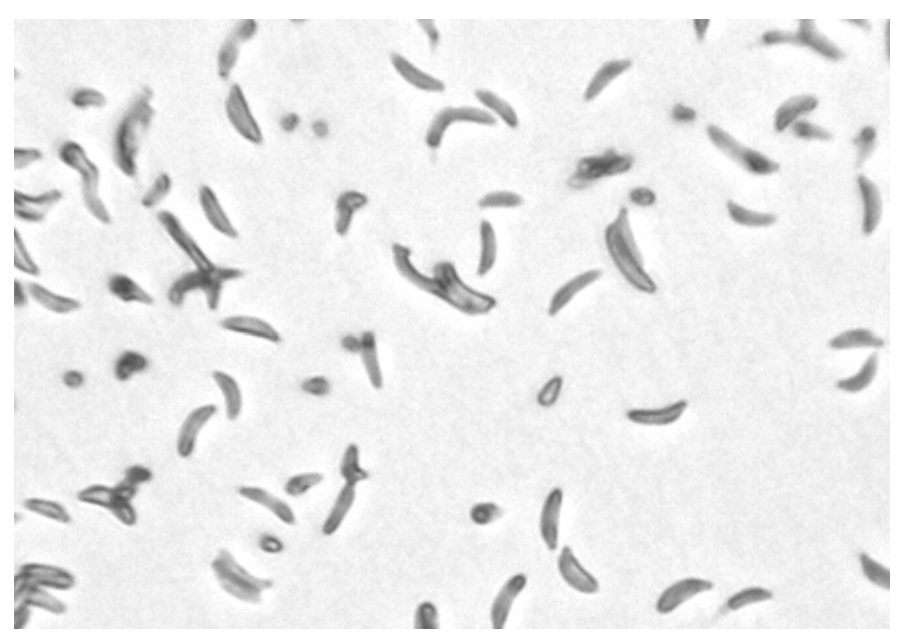

Fig. 5. Secondary sporidia of Tilletia indica on the surface of a petri dish lid after incubation in the Maricopa, AZ field for 49 days. The sporidia appear similar to those observed the day they were dried in the lab before placing them in the field.
95\% RH, and sporidia had much shorter survival time when incubated at lower humidity. This is in contrast to what was found in the current experiments that demonstrated secondary sporidia to be quite durable after long periods of very dry conditions in the laboratory or after extensive exposure to hot and dry field environments after crop maturity. In addition to the results described here, numerous similar preliminary laboratory experiments were conducted with secondary sporidia at 10 to $20 \%$ RH that demonstrated survival up to 25 days when samples became depleted, preventing further assays (data not shown).

Durability of $T$. indica hyphae or sporidia has been suggested by two recent studies. Kaur et al. (24) showed that $T$. indica colonies survived up to 19 days on moist muslin within beakers that were placed within a green crop canopy. Temperature and $\mathrm{RH}$ recorded at nearby weather stations ranged from 10 to $22^{\circ} \mathrm{C}$ and 58 to $94 \%$ RH, however canopy humidity was likely much higher. A preliminary report of the current studies (16) led to experiments where sporidia dried on plants for up to 5 days in a greenhouse maintained at a mean of $27 \% \mathrm{RH}$ were found to be viable and able to cause disease after incubation overnight in a dew chamber (30).

The concept of the fragility of secondary sporidia has led to the thought that in order for viable sporidial inoculum to be available the teliospores of T. horrida and T. indica must germinate during, or just prior to, the susceptible heading stages to avoid desiccation and death of the sporidia $(2,11,13,14,22,34,37)$. The term "suicidal germination" has been used to describe the fate of the pathogen when teliospores germinate outside of the susceptible heading period $(11,21,32,41)$. Furthermore, it has been suggested that there must be some sort of "safety mechanism" or "timing mechanism" to stimulate teliospore germination of T. horrida and T. indica during heading to ensure that viable inoculum is present during susceptible plant stages $(42,43)$. There has been no research yet presented that attempts to confirm these ideas, but there are reports of research on teliospore germination that appears to refute these hypotheses. In the species studied here, teliospore germination occurs after approximately 5 days at $20^{\circ} \mathrm{C}$ under optimal laboratory conditions (8). Teliospores of $T$. indica germinate in vitro over a wide range of conditions in soil moisture, temperature, and $\mathrm{pH}$, and also during incubation that includes cycles of freezing and thawing, and high moisture and desiccation $(13,31,38,44)$. Teliospores of $T$. indica have been found to germinate on soil under field conditions in India at about the same rate from mid-December to the end of February, which coincides with the period shortly after planting through wheat heading (25). These results are not consistent with hypotheses that teliospores are stimulated to germinate during susceptible plant stages. Teliospores likely germinate under natural conditions whenever moisture and temperature are conducive, regardless of the condition of the host. The durability of secondary sporidia demonstrated in the current experiments could represent an example of the hypothesized safety mechanism.

Experiments performed with sporidia produced from both WA and PDA cultures enabled the evaluation of potential osmotic or nutrition effects on the eventual regeneration of sporidia. No noticeable effects of culture media on the vigor or longevity of dried sporidia were observed.

The results of these experiments present new information that demonstrate secondary sporidia, the infective agents of the respective diseases, are highly durable under fairly extreme natural and laboratory environments. This information indicates that the persistence of secondary sporidia may have a substantial role in disease epidemiology. It appears that teliospores that germinate and produce hyphae and secondary sporidia well in advance of the susceptible heading period of plants could produce effective sporidial inoculum that can lay dormant in field environments for extensive periods, and then rapidly regenerate during humid, rainy conditions normally associated with the diseases. Disease pre- 
diction models have been developed which include climatic factors of temperature, humidity, solar radiation, and rainfall during heading of wheat $(19,20,27)$ which influence the production of secondary sporidia in the canopy.

Secondary sporidia of the wheat common bunt fungus $T$. tritici was used in several of the experiments conducted here. T. contraversa, the dwarf bunt fungus, was tested separately in one experiment. These fungi showed similar durability (data not shown) as was determined for the floret infecting species. The common bunt and dwarf bunt fungi have secondary sporidia with essentially the same morphology as the floret infecting species but have an entirely different etiology. With these fungi, initial infection of seedlings occurs either prior to plant emergence, as with common bunt, or after plant emergence beneath snow cover, as with dwarf bunt. This indicates a potential for infection without recent teliospore germination with these fungi as well.

The durability of secondary sporidia demonstrated here appears to correspond with information reported in other smut fungi which suggests a potential for sporidia or hyphae to act as infecting agents in the absence of recently germinated teliospores. In the corn smut fungus, Ustilago maydis, haploid cells (sporidia) appear to survive in soil throughout the year $(26,40)$. Survival of $T$. contraversa and $T$. tritici mycelia dried on filter paper and stored at 4 to $5^{\circ} \mathrm{C}$ has been reported (3). The dry dormant mycelium of loose smut fungi of wheat and barley, which remains viable for years in seed and then rejuvenates as seed germinates, is another example of hyphal durability of smut fungi.

\section{ACKNOWLEDGMENTS}

The assistance of T. Boratynski, USDA-APHIS, and R. Ykema, Arizona Department of Agriculture, with the experiments in Arizona was essential for the success of this work. I thank G. Peterson for allowing the use of the experimental field in Maricopa, AZ. The pathogens used in this study were provided by F. Lee (T. horrida), R. Ykema (T. indica), and L. Carris (T. walkeri). K. Cichy kindly assisted with the figures for the manuscript.

\section{LITERATURE CITED}

1. Aujla, S. S., Kaur, S., Singh, G., and Gill, K. S. 1987. Structural relationships and fusions in Neovossia indica prior to host penetration in relation to relative humidity. Indian J. Ecol. 14:129-135.

2. Baker, R. H. A., Sansford, C. E., Gioli, B., Miglietta, F., Porter, J. R., and Ewert, F. 2005. Combining a disease model with a crop phenology model to assess and map pest risk: Karnal bunt disease (Tilletia indica) of wheat in Europe. 2005 BCPC Symp. Proc. No. 81:89-94.

3. Blaskova, V. 1996. Vliv genotypu ozime psenice (Triticum aestivum L.) na vyskyt sneti rodu Tilletia v Ceske republice. Diploma thesis, Charles University, Prague, Faculty of Science, Department of Botany, Prague.

4. Biswas, A. 2003. Kernel smut disease of rice: Current status and future challengers. Environ. Ecol. 21:336-351.

5. Bonde, M. R., Berner, D. K., Nester, S. E., Peterson, G. L., Olsen, M. W., Cunger, B. M., and Sim, T. 2004. Survival of Tilletia indica teliospores in different soils. Plant Dis. 88:316-324.

6. Bonde, M. R., Peterson, G. L., Schaad, N. W., and Smilanick, J. L. 1997. Karnal bunt of wheat. Plant Dis. 81:1370-1377.

7. Brennan, J. P., and Warham, E. J. 1990. Economic losses from Karnal bunt in Mexico. Centro Internaicional de Mejoramiento de Maiz y Trigo. CIMMYT Economic Working Paper 90/2. El Batan, Texcoco, Mexico.

8. Carris, L. M., Castlebury, L. A., and Goates, B. J. 2006. Nonsystemic bunt fungi-Tilletia indica and T. horrida: A review of history, systematics, and biology. Ann. Rev. Phytopathol. 44:113-133.

9. Castlebury, L. A., and Carris, L. M. 1999. Tilletia walkeri, a new species on Lolium multiflorum and L. perenne. Mycologia 91:121-131.

10. Castlebury, L. A., Carris, L. M., and Vanky, K. 2005. Phylogenetic analysis of Tilletia and allied genera in order Tilletiales (Ustilaginomycetes; Exobasidiomycetidae) based on large subunit nuclear rDNA sequences. Mycologia 97:888-900.

11. Chahal, S. S. 2001. Epidemiology and management of two cereal bunts. Indian Phytopathol. 54:145-157.

12. Dhaliwal, H. S. 1988. Multiplication of secondary sporidia of Tilletia indica on soil and wheat leaves and spikes and incidence of Karnal bunt.
Can. J. Bot. 67:2387-2390.

13. Dupler, M., Smilanick, J. L., and Hoffmann, J. A. 1987. Effect of matric and osmotic potential on teliospore germination of Tilletia indica. Phytopathology 77:594-598.

14. Gill, K. S., Sharma, I., and Aujla, S. S. 1993. Karnal Bunt and Wheat Production. Punjab Agricultural University Press, Ludhiana, Punjab, India.

15. Goates, B. J. 1988. Histology of infection of wheat by Tilletia indica, the Karnal bunt pathogen. Phytopathology 78:1434-1441.

16. Goates, B. J. 2006. Anomalous and new epidemiological relationships of seed diseases caused by Tilletia species. (Abstr.) Phytopathology 96(suppl.):S132.

17. Goates, B. J., and Hoffmann, J. A. 1986. Formation and discharge of secondary sporidia of the bunt fungus, Tilletia foetida. Mycologia 78:371379 .

18. Goates, B. J., and Jackson, E. W. 2006. Susceptibility of wheat to Tilletia indica during stages of plant development. Phytopathology 96:962-966.

19. Jhorar, O. P., Mavi, H. S., Sharma, I., Mahi, G. S., Mathauda, S. S., and Singh, G. 1992. A biometeorological model for forecasting Karnal bunt disease of wheat. Plant Dis. Res. 7:204-209.

20. Jhorar, O. P., Sharma, I., Mavi, H. S., Aujla, S. S., and Nanda, G. S. 1993. Forecasting models for effective application of fungitoxicant in the management of Karnal bunt. Indian J. Mycol. Plant Pathol. 23:78-89.

21. Jones, D. R. 2009. Toward a more reasoned assessment of the threat to wheat crops from Tilletia indica, the cause of Karnal bunt disease. Eur. J. Plant Pathol. 123:247-259.

22. Joshi, L. M., Singh, D. V, Srivastava, K. D., and Wilcoxson, R. D. 1983. Karnal bunt: A minor disease that is now a major threat to wheat. Bot. Rev. 49:309-330.

23. Kaur, G., and Kaur, S. 2005. Simulating natural infection of wheat ovaries with Tilletia indica and interaction with date of sowing and varieties. Crop Improv. 32:26-34.

24. Kaur, G., Kaur, S., and Hundal, S. S. 2007. Weather-based empirical model to predict infective sporidial stage of Tilletia indica during wheat crop season. Indian Phytopathol. 60:173-179.

25. Kaur, S., Singh, M., and Singh, K. 2002. Factors affecting telial and sporidial inoculum of Neovossia indica. Indian Phytopathol. 55:14-18.

26. Marchese, R., McLaughlin, J., Voisey, L., Gorgol, L., McCann, M., and Snetselaar, K. 2004. Isolation of Ustilago maydis from soil. Inoculum 55:26.

27. Mavi, H. S., Jhorar, O. P., Sharma, I., Singh, G., and Mahi, G. S. 1992. Forecasting Karnal bunt disease of wheat: A meteorological method. Cereal Res. Commun. 20:67-74.

28. Nagarajan, S. 2001. Pest risk analysis for shipping wheat from Karnal bunt (Tilletia indica) infected areas to disease free destinations. A report of consultancy project extended to Dr. S. Nagarajan vide F. No. 2 (30)/2000. I.C.I. dt. 19. 01. 2001. of ICAR, New Delhi.

29. Nagarajan, S., Aujla, S. S., Nanda, G. S., Sharma, I., Goel, L. B., Kumar, J., and Singh, D. V. 1997. Karnal bunt (Tilletia indica) of wheat-A review. Rev. Plant Pathol. 76:1207-1214.

30. Peterson, G. L., and Glenn, D. L. 2008. Tilletia indica: Resiliency of allantoid sporidia and its relationship to wheat infection. (Abstr.) Phytopathology 98(suppl.):S125.

31. Rattan, G. S., and Aujla, S. S. 1992. Ecology and germination of the teliospore of Karnal-bunt pathogen (Neovossia indica). Indian J. Agric. Sci. 62:228-231.

32. Rush, C. M., Stein, J. M., Bowden, R. L., Riemenschneider, R., Borartynski, T., and Royer, M. H. 2005. Status of Karnal bunt of wheat in the United States 1996 to 2004. Plant Dis. 89:212-223.

33. Sansford, C., Baker, R., Brennan, J., Ewert, F., Gioli, B., Inman, A., Kelly, P., Kinsella, A., Leth, V., Magnus, H., Miglietta, F., Murray, G., Peterson, G., Porta-Puglia, A., Porter, J., Rafoss, T., Riccioni, L., Thorne, F., and Valvassori, M. 2006. Risks associated with Tilletia indica, the newlylisted EU quarantine pathogen, the cause of Karnal bunt of wheat. EC Fifth Framework Project QLK5-1999-10554.

34. Sharma, A. K., Kumar, J., and Nagarajan, S. 1998. Worldwide movement of smuts and bunts. Pages 129-135. In: Bunts and Smuts of Wheat: An International Symposium. V. S. Malik and D. E. Mathre, eds. North American Plant Protection Organization, Ottawa.

35. Singh, D. V. 2005. Karnal bunt of wheat: A global perspective. Indian Phytopathol. 58:1-9.

36. Singh, R. A. 1975. Source of inoculum and the epidemiology of bunt of rice. Riso 25:77-80.

37. Singh, R. A., and Pavgi, M. S. 1970. Varietal reaction and resistance to kernel bunt of rice. Indian Phytopathology 23:51-53.

38. Smilanick, J. L., Hoffmann, J. A., and Royer, M. H. 1985. Effect of temperature, $\mathrm{pH}$, light, and desiccation on teliospore germination of Tilletia indica. Phytopathology 75:1428-1431.

39. Smilanick, J. L., Prescott, J. M., Hoffmann, J. A., Secrest, L. R., and Weise, K. 1989. Environmental effects on survival and growth of 
secondary sporidia and teliospores of Tilletia indica. Crop Prot. 8:86-90.

40. Snetselaar, K., Gorgol, L., Petrella, K., Marchese, R., Wierbowski, C. Voisey, L., and McCann, M. 2004. Survival of Ustilago maydis propagules in soil. Page 19 in: Proc. XIVth Biennial Workshop on the Smut Fungi. Idaho Falls, Idaho.

41. Stein, J. M., Maples, H. W., and Rush, C. M. 2005. Epidemiology of Tilletia indica in regulated wheat fields in Texas. Plant Dis. 89:828-833.
42. Warham, E. J. 1988. Teliospore germination patterns in Tilletia indica. Trans. Br. Mycol. Soc. 90:318-320.

43. Whitney, N. G., and Frederiksen, R. A. 1975. Kernel smut of rice. Tex. Agric. Exp. Stn. Misc. Publ. 1231.

44. Zhang, Z., Lange, L., Mathur, S. B. 1984. Teliospore survival and plant quarantine significance to Tilletia indica (causal agent of Karnal bunt) particularly in relation to China. EPPO Bull. 14:119-128. 